Proc. Indian Acad. Sci., Vol. 87 A (E \& P Sciences-4), No. 11, November 1978, pp. 201-213, (C) printed in India

\title{
Susceptibility as a tool for studying magnetic stratigraphy of marine sediments
}

\author{
B L K SOMAYAJULU, C RADHAKRISHNAMURTY* and \\ T J WALSH $†$ \\ Physical Research Laboratory, Ahmedabad 380009 \\ *Tata Institute of Fundamental Research, Bombay 400005 \\ †Scripps Institution of Oceanography, La Jolla, California 92093, USA
}

MS received 17 March 1978; revised 21 August 1978

\begin{abstract}
Eighty six gravity cores collected from the Pacific Ocean by the Scripps Institution of Oceanography have been logged for magnetic susceptibility using a simple and rapid technique. These logs fall into three types:-Type 1 showing several highs and lows, Type 2 with a single-broad-hump, and Type 3 showing nearly constant susceptibility with depth.

Type 1 cores are found to be mainly from sediment-trap (trenches) areas which are close to the active volcanoes and the high peaks probably correspond to a slump of deposition of volcanic material; these events occurred between 0.1 and $2 \cdot 8$ million years ago.

Type 2 cores are by far the most common, ( 56 out of 86 ) and show a maximum deposition of magnetic material (i.e. crest region of the hump) in the range of 0.2 and 1.7 million years. The susceptibility during this period was about a factor of two higher for several cores compared to their respective values during the last 0.1 million years. Oceanwide deposition of volcanic material and/or the atmospherically transported dust rich in magnetic material (cosmic and/or terrestrial) by our planet can account for such an increase. A third possibility may be the change (decrease) in accumulation rates of the sediments during this period.

In type 3 cores the susceptibility is almost constant with depth and these are raindomly distributed (excluding the sediment trap areas) analogous to the case of type 2 cores. A high deposition rate in these areas can alter type 2 into type 3.

It appears that the maximum of type 2 hump can act as a stratigraphic marker since type 2 cores are the most common ones and are widely distributed over the entire Pacific.
\end{abstract}

Keywords. Susceptibility; maguetism; stratigraphy; Pacific sediments.

\section{Introdaction}

Radhakrishnamurty et al (1968) had shown that the variation of magnetic susceptibility (termed susceptibility henceforth) of marine sediments with depth can be conveniently studied by a simple and rapid logging technique. With this technique it was possible to show that: (i) the susceptibility variation in a long sediment core of any diameter could be determined (using suitable double coils) with a high sensitivity and, (ii) for magnetic reversal studies cores showing large variations of susceptibility along the entire length are unsuitable; also such cores generally do not conform to the $Q_{n}$ criterion (Amin et al 1972).

Magnetic reversals in marine sediments have already been proven to be a powerful stratigraphic tool which in turn can be correlated to the biostratigraphy (Opdyke 
1972) and paleoclimates (Doake 1977, 1978). In the recent years it was also realised that volcanic activity has something to do with climatic change (Bray 1977; Kelly 1977). Both recent volcanic eruptions (Hansen et al 1978) and pleistocene volcanic ash distribution in marine sediments seem to correlate reasonably well with climatic changes.

It is well known that volcanic material is richer in magnetic minerals compared to other terrestrial material. Hence it was felt that the magnetic susceptibility logging of marine sediments could be an easier way for ascertaining paleovolcanic activity besides understanding cosmic material accumulation on the ocean floor as well as serving as stratigraphic markers. As a first step in this direction we have logged 86 gravity cores from the Pacific Ocean available from the collections of the Scripps Institution of Oceanography, the results of which are discussed in detail.

\section{Experimental techniques}

The apparatus used in the present study is almost identical to the one developed by Radhakrishnamurty et al (1968), but for the transistorised electronic unit and double coils of different sizes. Details of the instrument and experimental procedures have been previously described by Likhite (1965), Likhite and Radhakrishnamurty (1965), and Radhakrishnamurty et al (1968). The instrument essentially consists of a well balanced double coil situated at the centre of a large Helmoltz coil carrying a sinusoidal current. In this condition the output of the double coil can be made practically zero. If a core sample is now placed in the double coil, the sample behaves like an alternating dipole and induces a differential emf which is proportional to the magnetic moment of the sample. However, in the case of a continuous long core, a portion of the core which is slightly more than the volume enclosed by the double coil could contribute to the differential emf. It was experimentally found that a $2 \mathrm{~cm}$ wide double coil could detect even thin bands of magnetic material in sediment cores. The signal from the double coil is amplified and displayed on an oscilloscope screen as well as rectified and read out with a microammeter. Since the cross-section of the core is uniform, the signals are proportional to the susceptibility of the portion of the core material enclosed by the double coil. The instrument has an inherent sensitivity to measure a volume susceptibility of $10^{-7} \mathrm{cgs}$ units with an accuracy of about $5 \%$. But for susceptibility logging purposes, the sensitivity required is much less and is usually adjusted to suit the particular core. Measurements are made at every $2 \mathrm{~cm}$ length of the core and they are only given in relative arbitrary units, since the main purpose of logging is to detect the variations. It takes about $20-30 \mathrm{~min}$ to complete measurements on a $150 \mathrm{~cm}$ long core.

Figure 1 is a photograph of the instrument assembly in use during the measurements at the Scripps Institution of Oceanography.

\section{Results}

Susceptibility (in relative units) is plotted as a function of depth for all the cores individually and these plots are shown in figure 2 . For convenience the cores are listed from 1 to 86 and these numbers appear in figures 2 and 3 ( $a, b$ and $c$ ) from 


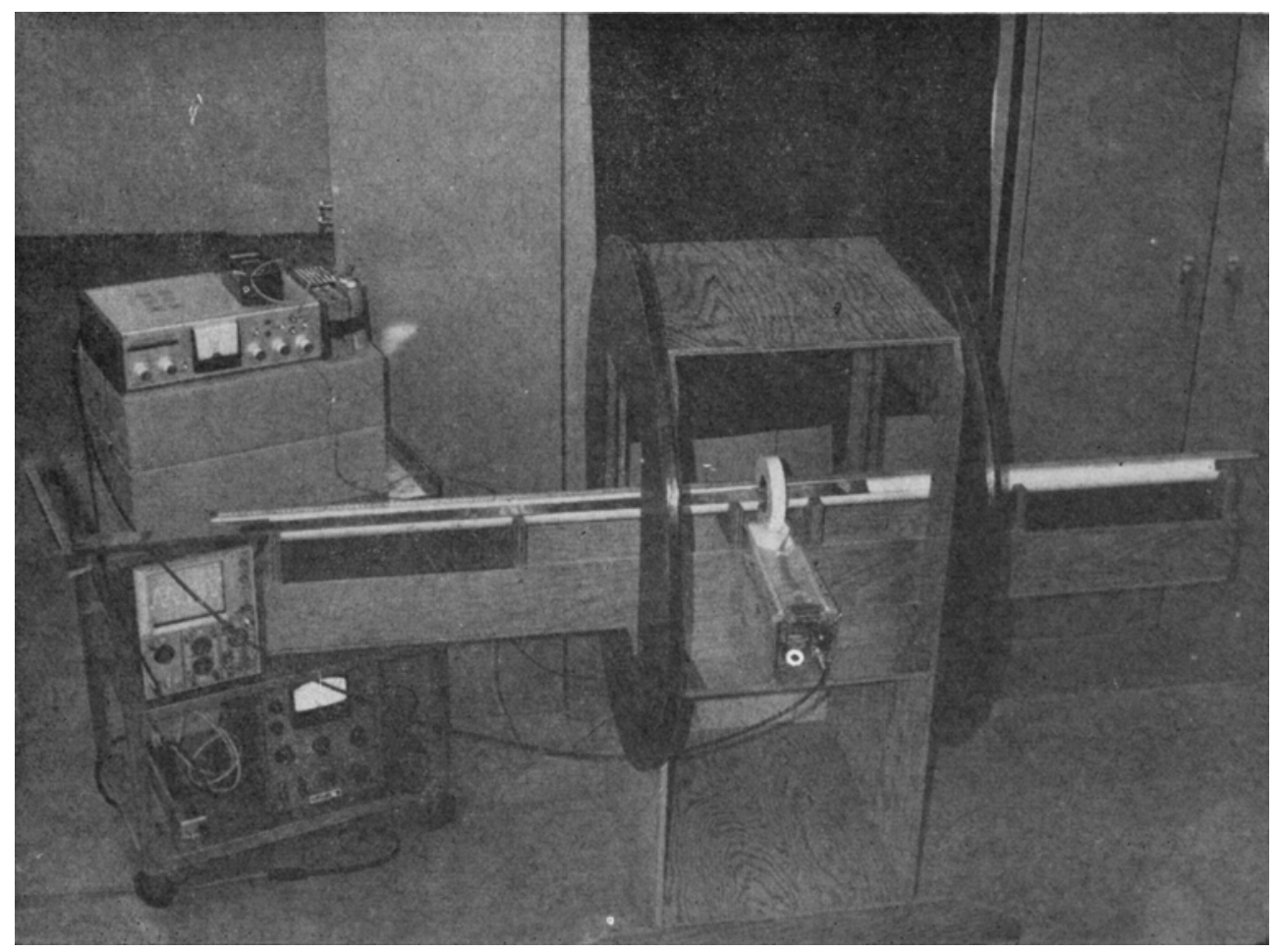

Figure 1. Experimental set-up for magnetic susceptibility logging. Note the different colour zones in the core. The differential emf is displayed on the oscilloscope. The ammeter reads susceptibility (in relative units). 
which all the necessary information can be obtained. Before discussing the results, however, it is important to mention the reproducibility and reliability of the susceptibility instrument.

Repeat measurements using a given double coil were made several times and the respective logs were identical; whenever the sensitivity of the instrument was increased the highs and lows were more pronounced, as expected.

A set of six gravity cores (serial numbers 26-31) collected from the DELO Expedition at $39^{\circ} \mathrm{N} ; 128^{\circ} \mathrm{W}$ showed almost identical logs (figure 2). A second set of three cores (Nos 43-45) collected from the equatorial region at $86^{\circ} \mathrm{W}$ also showed identical logs. One would expect that at almost the same location the logs should be identical if the instrument is reliable.

\section{Discossion}

Based on the individuals susceptibility logs (figure 2 ) and from the locations and details of the cores the following generaisations can be made.

(1) The susceptibility log is independent of the type, texture, colour and probably bulk composition of the core. In several cores with variable physical characteristics such as colour and texture the susceptibility logs showed the same pattern. In five of the cores (Nos 10,17,61,81 and 82-figure 2) used in this work there is a manganese nodule (diameter $1 \mathrm{~cm}$ ). The susceptibility logs, however, showed no change in

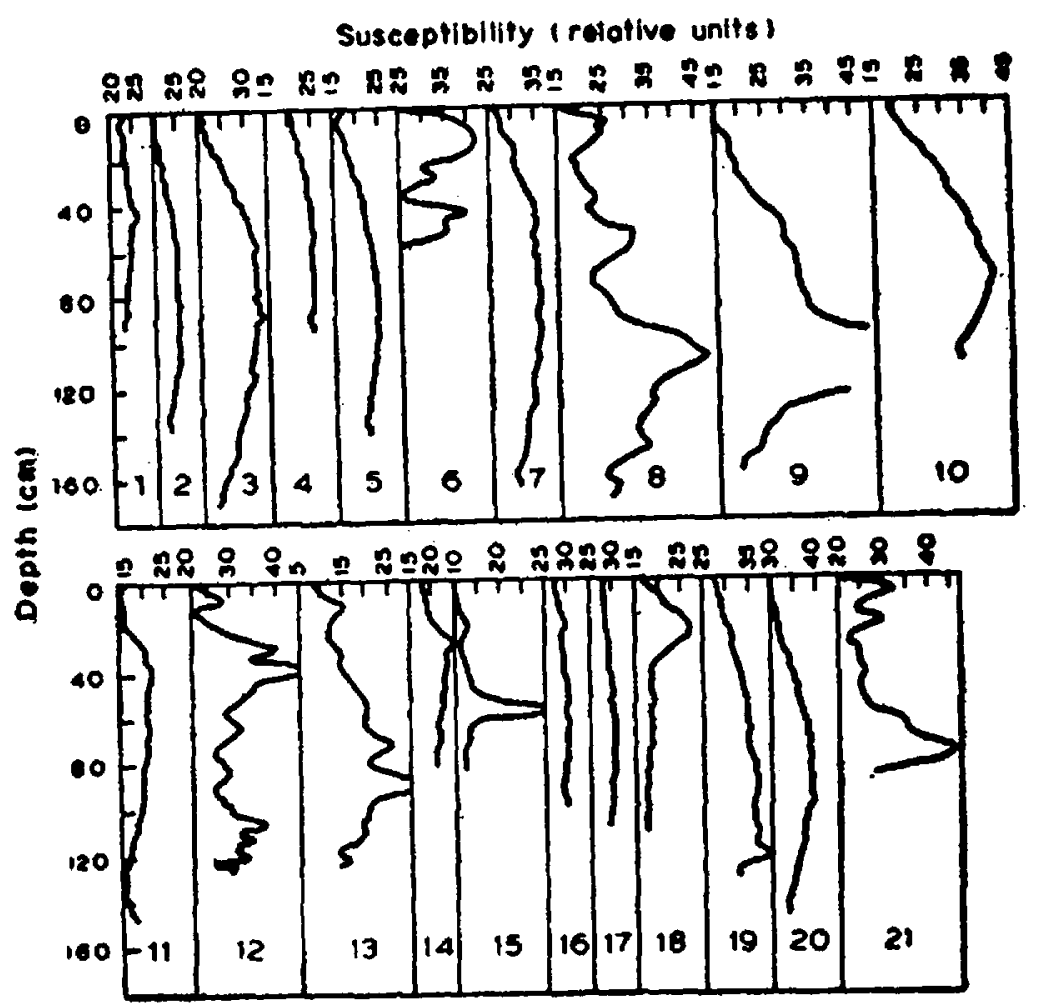

Figure 2a. 
the pattern in these cores compared to others without nodules. This observation indicates that the susceptibility of the nodule material is not significantly different from that of the surrounding sedimentary material.

(2) In general the susceptibility logs fall into three types (Somayajulu et al 1975): type 1 showing several highs and lows: type 2 with a single-broad-hump; and type 3 where the susceptibility shows no variation with depth. All the three types of cores are indicated in figures $3 a, b$ and $c$ respectively.

(3) In almost all cases it appears that the susceptibility in the past (older than about $10^{5}$ years) was high compared to the present level (figure 2). We have not considered the logs for the $3 \mathrm{~cm}$ end portions of each core since, in general, the susceptibility values as measured by this technique show lower values at the veryend-zones of the cores.

The three types of logs encountered in this study are discussed below.

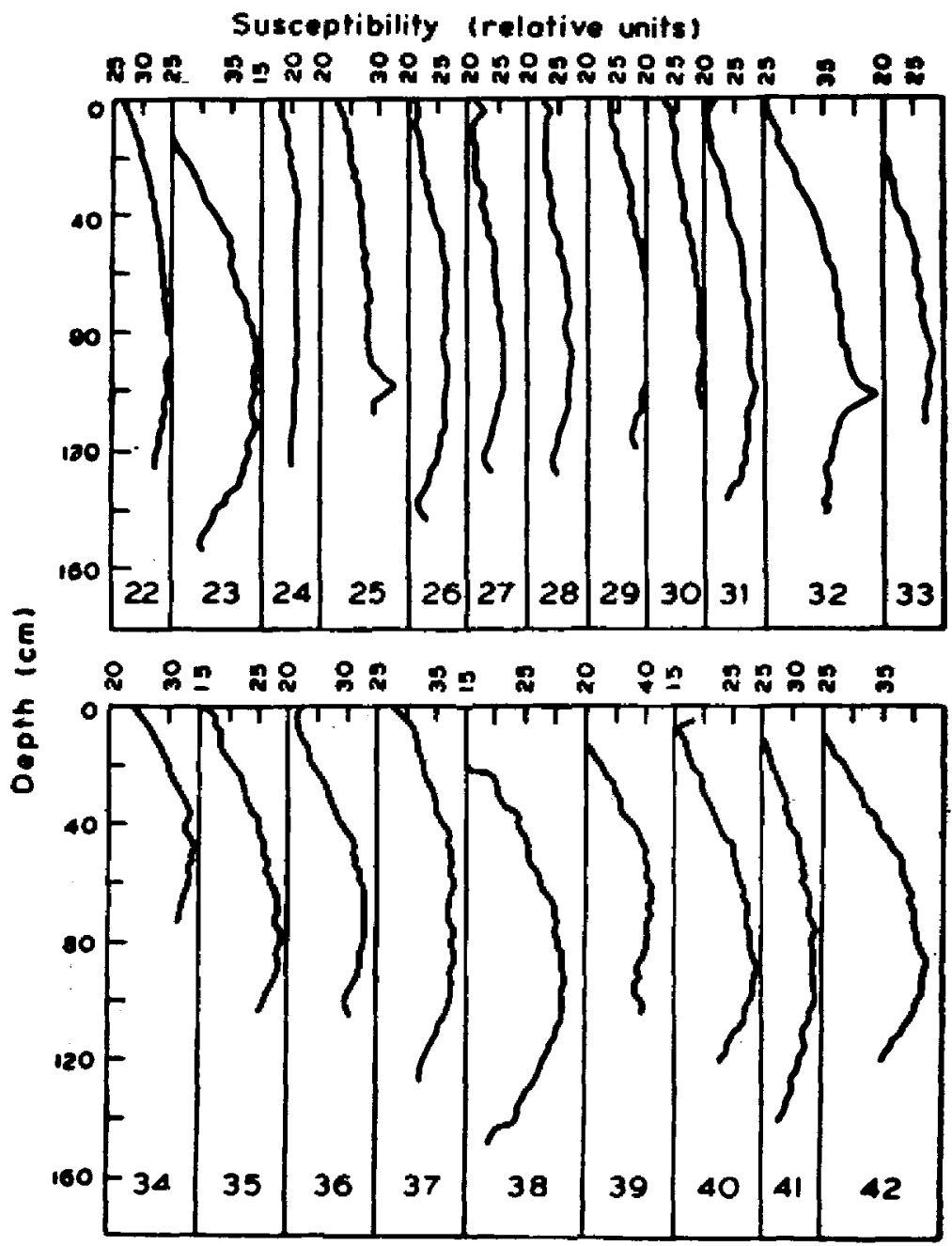

Figure $2 \mathbf{b}$. 


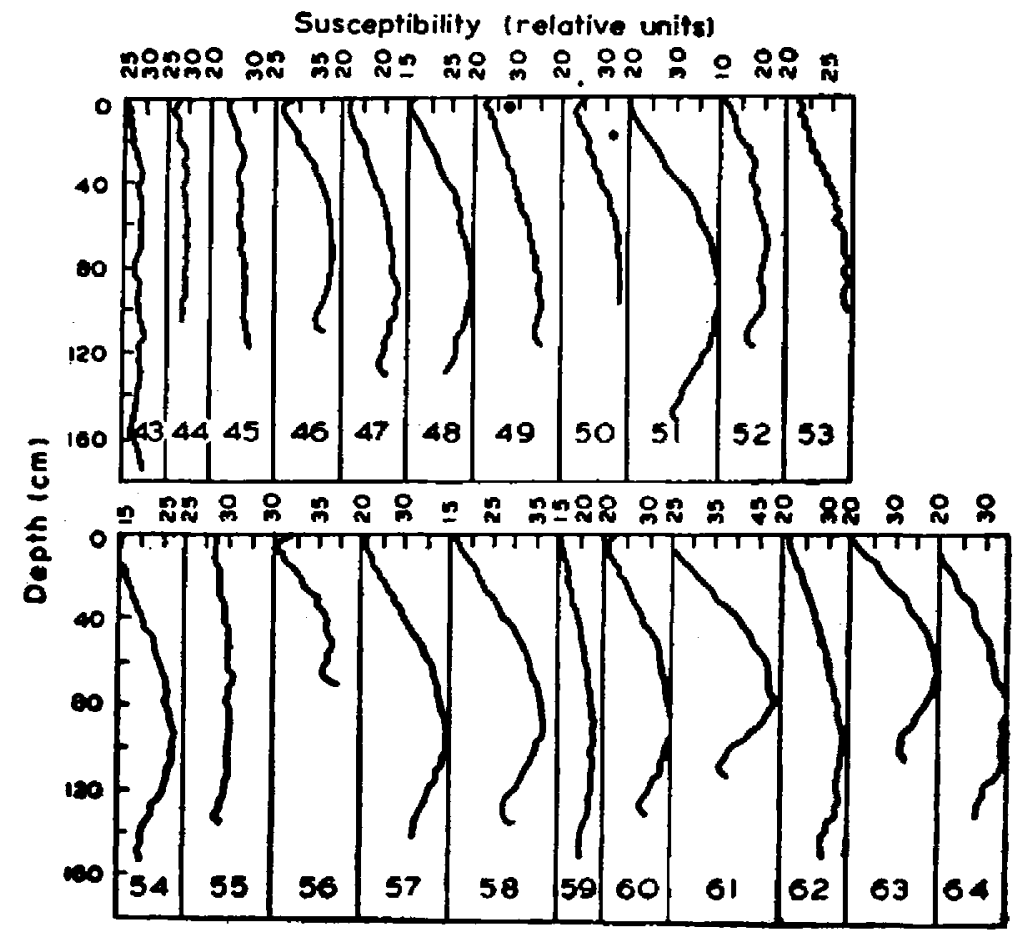

(2c)

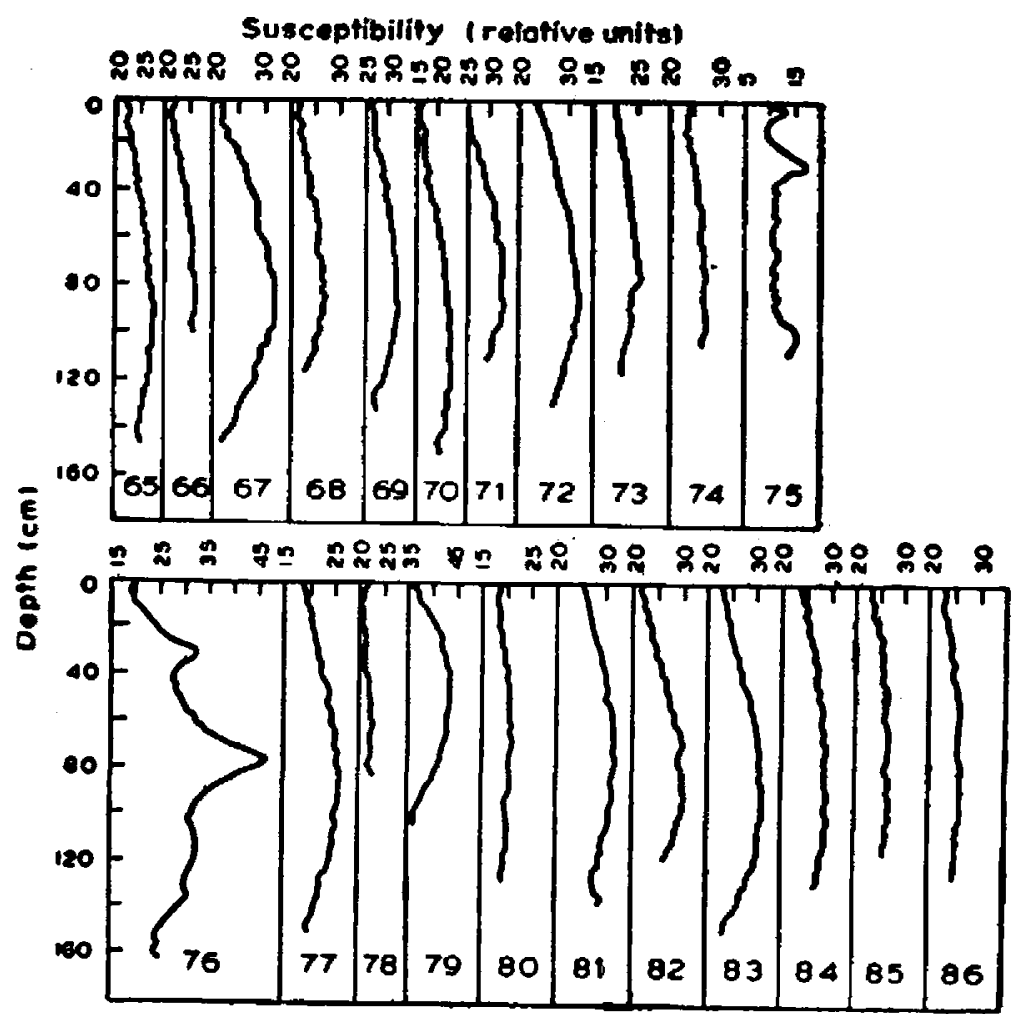

(2d)

Figure 2. Individual magnetic susceptibility lops of all the 86 gravity cores. 


\subsection{Type 1 logs}

Fifteen (Nos 6, 8, 9, 11, 12, 13, 14, 15, 18, 19, 21, 25, 32, 75 and 76-see figures 2 and $3 a)$ of the 86 cores belong to this category. All these cores are located in the trench and associated sediment trap areas (Fisher and Hess 1963; Menard 1964), along the plate boundaries as defined by the earthquake epicenters (Vacquier 1972). These cores are also located close to active volcanoes in the Pacific as shown in figure 3a (Macdonald 1972). These cores, by virtue of their location, would hold records for episodes involving deposition-(or slump) rich in volcanic activity. The high peaks in these cores may indeed be indications of such episodes. The material deposited should be most probably volcanic which has higher susceptibility. It is also evident from the clay mineral distributions in the Pacific (Griffin et al 1968) that most of the surface sediments in the areas covered by trenches have substantial amounts $(30-50 \%$ in less than 2 micron fraction) of montmorillonite. It will be very worthwhile to analyse this mineral, diagnostic of volcanic activity, as a function of depth in the cores of type 1 and see if the peaks in susceptibility correspond to high montmorillonite contents.

4.1.1 Frequency of the high susceptibility events: There is more than one event of high susceptibility occurrence in most of the type 1 cores. In order to bring in the time parameter for these events, we have surveyed the literature on the accumulation rates of Pacific sediments and have assigned rates for different regions of the Pacific; these rates are given in table 1 . The high susceptiblity events have occurred between $1.1 \times 10^{5}$ and $2.8 \times 10^{6}$ years some times synchronously at different regions. In figure 4 the frequency distribution of the number of cores having an event as a function of time is shown. It is clear from figure 4 that during the past $0.1-0.5$ million years and in general till 1.5 million years the high susceptibility events occurred over a larger area; events beyond 1.5 million years were more localized. This observation is well supported by that of Kennett and Thunnel

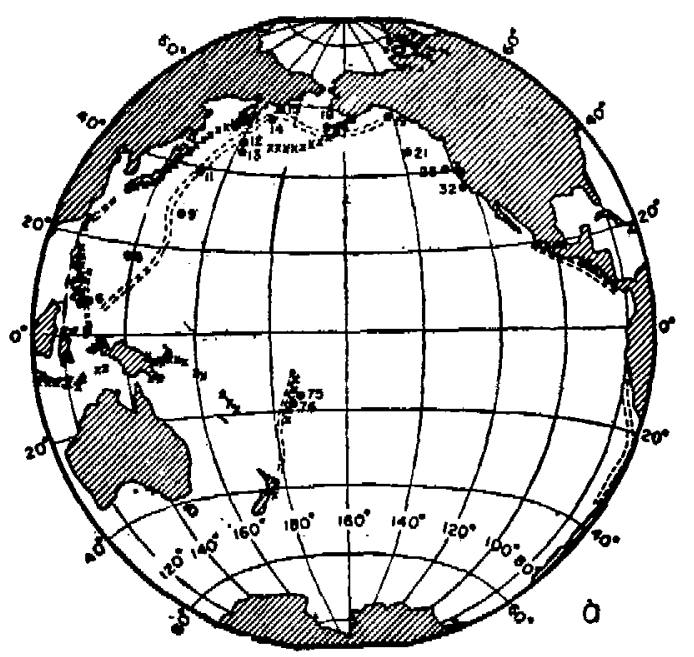

Figure 3a. 

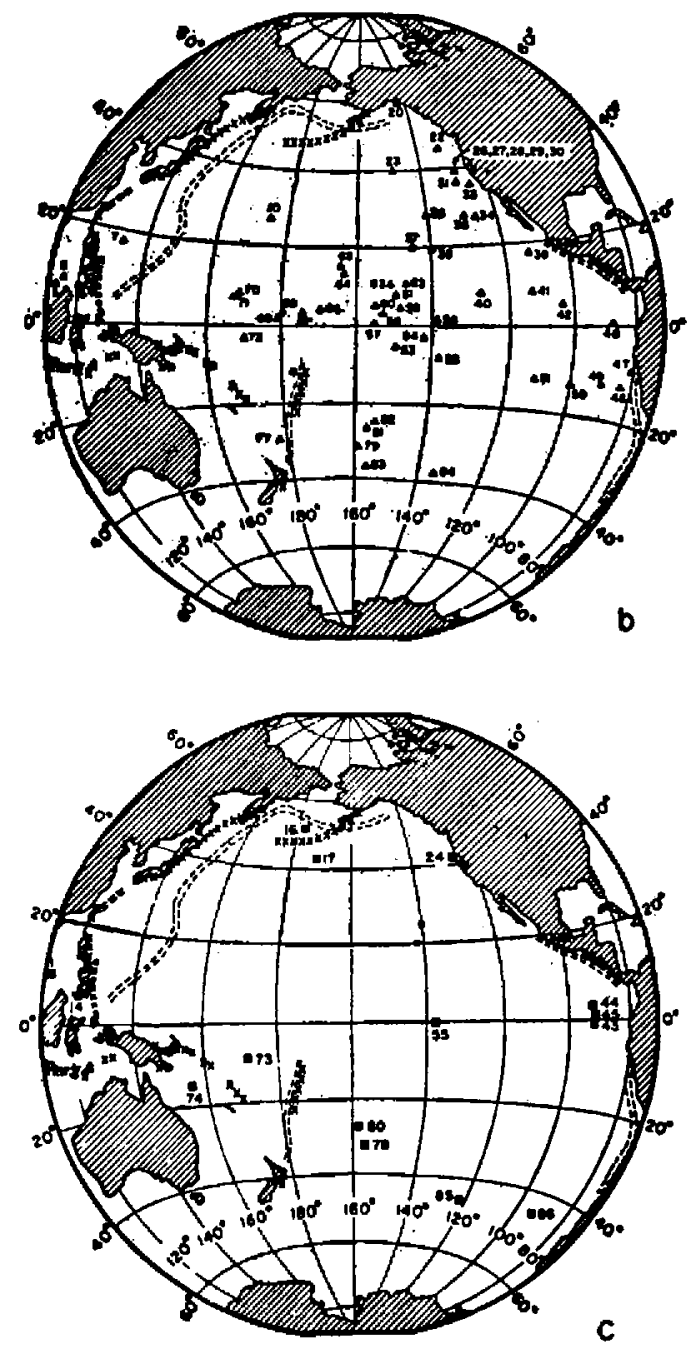

Figure 3. Map of the Pacific ocean showing the principal trench systems (indicated by double dashed lines) and active volcanoes shown as Xes. a. Shows the distribution of type 1 logs. b. shows type 2 logs and c. type 3 logs. See discussion for details.

(1977) as well as of Bray (1977) who found a more frequent occurrence in volcanic ash layers in deep sea sediments. Since only gravity cores (about $150 \mathrm{~cm}$ in length on the average) have been studied in the present investigation, we have missed most other older events $\left(2.5 \times 10^{6}\right.$ years); it is planned to extend this study to piston cores and also to the DSDP cores.

\subsection{Type 2 logs}

These are by far the most common ones. 56 (Nos 2, 3, 5, 7, 10, 20, 22, 23, 26-31, $33-42,46-54,56-72,77,79$ and 81-84-figures 2 and $3 \mathrm{~b}$ ) cores show a broad-hump. the maximum of which ranges anywhere between $40 \mathrm{~cm}$ to $120 \mathrm{~cm}$. In terms of age 
Table 1. Accumulation rates in various regions of the Pacific.

\begin{tabular}{lcc}
\hline Kegion & $\begin{array}{c}\text { Core } \\
\text { numbers* }\end{array}$ & $\begin{array}{c}\text { Accumulation } \\
\text { rate** } \\
\left(\mathrm{mm} / \mathbf{1 0}^{*} \text { years }\right)\end{array}$ \\
\hline North and North west & $6-23$ & $0 \cdot 6$ \\
North east and East & $24-47$ & $2 \cdot 0$ \\
Central Equatorial & $48-73$ & $1 \cdot 6$ \\
South & $73-86$ & $1 \cdot 0$
\end{tabular}

*See figure 3.

- Rates are assigned to each region taking into consideration the published values for the entire Pacific (Miyake and Sugimura 1961; Griffin et al 1968, Ku et al 1968; Amin et al 1975). The variation in accumulation rates between different cores from each region is in general, about a factor of two.

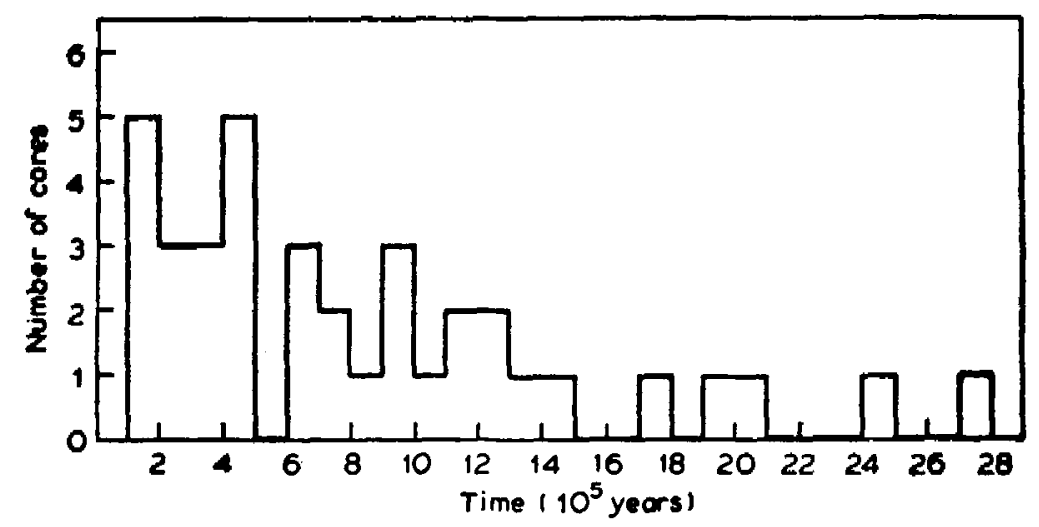

Figure 4. Frequency distribution of the number of cores with a high susceptibility event as a function of time. The 0.1-0.5 milition years event is more widespread in the Pacific. Older events appear to be more localised.

this means in the past, between 0.2 million years and 1.7 million years before present the magnetic material depositing on the Pacific ocean floor was higher. Based on the susceptibility logs we can estimate that this amount was higher by at least a factor of two compared to present level (i.e. before 0.1 million years). This phenomenon is not localised, it happened over the entire Pacific and is, as has been mentioned earlier, independent of the type, texture and composition (non-magnetic) of the sediment. As in the case of type 1, there are no sharp peaks but these maximum regions of the hump correspond in time to the peak events in type 1. Areas near the trench and other active volcanic regions figure $3 a$ ) would clearly register a volcanic event as a sharp peak whereas other distant areas will register only a smeared event which can appear as a broad-hump. Atmosphere can be a transporting agent for this material to the other neighbouring parts of the ocean as has been shown by Huang et al (1973) in the case of volcanic glass in South Pacific. Also the dispersion of volcanic aerosols into the stratosphere which provides test for global climatic perturbation was reported by Hansen et al (1978). Two other explanations are also possible: 
(i) The humps can be due to the increased influx of magnetic material transported through the atmosphere. Pettersson and Fredriksson (1958) detected magnetic spherules in deep sea sediments and havealso shown their depth variation (Arrhenius 1963). These were understood to be of cosmic origin. Similarly magnetic as well as nonmagnetic particles suggested to be originating from stony and iron meteorites were discovered in the slow-growing-ferromanganese nodules (Finkelman 1970). Direct collections of atmospheric dust on the other hand revealed that both cosmic and terrestrial (including industrial) particles are present in the magnetic fractions (Delany et al 1967). The studies of Bhat et al (1973) on manganese nodules coupled with those of Wanke (1966) on meteorites have indicated that the infiltration of cosmic material by the earth could have been high in the past. All the above information suggests that the flux of atmospherically transported magnetic material can vary, the variation manifesting as a broad-hump in the susceptibility log of the marine sediments.

(ii) The accumulation rates of marine sediments were changing (decreasing) during the maximum period of the hump. Though sharp changes in accumulation rates were predicted by ionium/thorium studies (Goldberg and Koide 1962)-a continuous change in accumulation rate has yet to be shown.

The recent compilation of the episodes of cenozoic volcanism by Kennet and Thunnel (1977) reveals high volcanic activity during the past 3 million years in the Southwest Pacific. The present study can thus show fine structure in such compilations and also indicate how wide such events were registered in deep sea sediments.

\subsection{Type 3 logs}

The remaining 15 cores (Nos $1,4,16,17,24,43-45,55,73,74,78,80,85$ and 86 figures 2 and 3 c) belong to this type. In a few cases, however, it is very hard to clearly distinguish these logs from the type 2 logs. In these cores which are distributed widely, there seem to be no appreciable variation in the magnetic material content depositing in the past. In view of the fact that most of the cores from all over the Pacific show the hump, it may be possible that in the type 3 cores there had been either some kind of mixing or that deposition rate were high such that the broad hump was smoothened out.

It is tempting to postulate, although not confirmed, that the position of maximum in the hump of the type 2 logs can be used as stratigraphic marker. If this is true sediments can be dated by ascertaining the depth at which the maximum occurs using the rapid logging technique in about $30 \mathrm{~min}$. Several cores belonging to type 2 would have to be dated by nuclear methods like ${ }^{40} \mathrm{~K}-{ }^{40} \mathrm{Ar}$ (Dymond 1966) and ${ }^{280} \mathrm{Th}$ (Goldberg and Koide 1962) to prove this hypothesis. For an up-to-date review of the dating techniques using the U-Th decay series' nuclides reference is made to $\mathrm{Ku}$ (1976).

\section{Conclusions}

World-ocean-wide studies of this type on piston and DSDP cores together with mineralogy, geochronology and diagnostic trace elemental analysis (Inoue and 
Tanaka 1976) will yield more information on the occurrence and time scales of high susceptibility events on a global scale. The volcanic and climatic effects in sediments can also be understood by carrying out ${ }^{10} \mathrm{Be}$ measurements (Somayajulu 1977) on some of the cores. One can also study the contribution of the weathering of oceanic crust to the basement of the sediment pile (Kemp et al 1974) using the susceptibility logging technique on DSDP cores. Chronology of ocean wide volcanic events can also be established which appears to have an important bearing on the global climate.

\section{Acknowledgements}

This work was supported in part by NSF-IDOE and was carried out when BLKS was at Scripps. The cores were collected during various expeditions of the Scripps Institution of Oceanography (supported by ONR NSF and AEC). We are grateful to Prof. W R Riedel for allowing the use of the cores reported in this study, to Profs. H Craig and D Lal for help and encouragement and to Drs Helmut Kueker, A Birket, E Hernandez, N F Cordeiro and S D Likhite for help with the set-up. We thank Dr R A Hart, Profs. S Krishnaswami and D Lal for discussions and criticism. We are indebted to Miss Suman Bhat of TIFR who most cheerfully plotted all the logs.

\section{References}

Amin B S, Likhite S D, Radhakrishnamurty C and Somayajulu B L K 1972 Deep Sea Res. 19249

Amin B S, Lal D and Somayajulu B L K 1975 Geochim. Cosmochim. Acta 391187

Arrhenius G 1963 in The Sea ed. M N Hill (New York: Interscience) 3655

Bhat S G, Krishnaswami S, Lal D, Rama and Somayajulu B L K 1973 in Proc. Int. Symp. Hydrogeochemistry and biogeochemistry, Tokyo (Washington: The Clarke \& Co.) 1443

Bray J R 1977 Science 197251

Delany A C, Delany A C, Perkin D W, Griffin J J, Goldberg E D and Reiman B E F 1967 Geochim. Cosmachim. Acta 31885

Doake C S M 1977 Nature, London 267415

Doake C S M 1978 Earth Planet. Sci. Lett. 38313

Dymond J R 1966 Science 1521239

Finkleman R 1970 Science 167982

Fisher R L and Hess H H 1963 in The Sea ed. M N Hill (New York: Wiley Interscience) 3411

Goldberg E D and Koide M 1962 Geochim. Cosmochim. Acta 28417

Griffin J J, Windom H L and Goldberg E D 1968 Deep Sea Res. 15433

Hansen J E, Wang W C and Lacis A A 1978 Science (in press)

Huang T C, Watkins N D, Shaw D M and Kennet J P 1973 Earth Planet. Set. Lett. 20119

Inoue T and Tanaka S 1976 Earth Planet. Sci. Lett, 29155

Kelly P M 1977 Nature, London 268616

Kemp D R C, Din V K, Eliott J C and Symes R F 1974 Initial reports of the deep sea drilling project 26

Kennett J P and Thunnel R C 1977 Science 1961231

Ku T L 1976 Ann. Rev. Earth Planet. Sci. 4347

Ku T L, Broecker W S and Opdyke N D 1968 Earth Planet. Sci. Lett. 41

Likhite S D 1968 M.Sc. Thesis Bombay Univ. pp. 66

Likhite S D and Radhakrishnamurty C 1965 Bull. Natl. Geophys. Res. Inst. 31

Macdonald G A 1972 Volcanoes (Univ. of Hawaii) pp. 429-450

Menard H W 1964 Marine geology of the Pacific (New York: McGraw Hill pp 271)

Miyake Y and Sugimura Y 1961 Science 1331823 
Opdyke N D 1972 Rev. Geophys. Space Phys. 10213

Pettersson H and Fredericksson K 1958 Pacific Sci. 1271

Radhakrishnamurty C, Likhite S D, Amin B S and Somayajulu B L K 1968 Earth Planet. Sci. Lett. 4464

Somayajulu B L K 1977 Geochim Cosmochim. Acta 41909

Somayajulu B L K, Walsh T J and Radhakrishnamurty C 1975 Nature, London 253616

Vacquier V 1972 Geomagnetism in marine geology (Elsevier): Oceanography Series 6 pp 185

Wanke H 1966 Fortschritte'd Chem. Forschung 7322

Proc. A. -3 